CASE REPORTS

\title{
Cardiac emergencies caused by honey ingestion: a single centre experience
}

\author{
H Özhan, R Akdemir, M Yazici, H Gündüz, S Duran, C Uyan
}

Emerg Med J 2004;21:742-744. doi: 10.1136/emj.2003.009324

An unusual type of food poisoning is commonly seen in the Black Sea coast of Turkey attributable to andromedotoxin containing toxic honey ingestion. This study is a retrospective case series of 19 patients admitted to an emergency department in 2002, poisoned by "mad" honey. All of the patients had the complaints of nausea, vomiting, sweating, dizziness, and weakness, several hours after ingesting "mad" honey. Physical examination showed hypotension in 15 patients, sinus bradycardia in 15, and complete atrioventricular block (AVB) in four patients on admission. Two patients with bradycardia and two with AVB fell and injured their heads. Three of them presented with local haematoma. One patient had a $6 \mathrm{~cm}$ cut on his head without any neurological deficit and his cranial computed tomography imaging was normal. Hypotension and conduction disorders resolved with atropine treatment, resulting in complete recovery within 24 hours.

$\mathrm{T}$ urkish honey from the Black Sea coast of Turkey, occasionally contains concentrations of acetylandromedol high enough to cause poisoning. Bradycardia, atrioventricular block (AVB), and arterial hypotension have the potential to cause death in untreated cases but no fatalities have been reported in the literature. Complete recovery after hospital admission is normally the rule because, hypotension usually responds to the administration of fluids, correction of bradycardia and conduction defects, which usually respond to atropine treatment. Most of the cases have been reported from Turkey. Sutlupinar et al reported 11 cases admitted to a hospital in Istanbul, between 1983 and 1988. ${ }^{1}$ Von Malottki et al reported a case from Germany and Gossinger et al reported two cases from Austria all treated successfully. ${ }^{2}$ Geroulanos et al from Switzerland reported that about eight cases of intoxication induced by honey have been reported in the hospital of Trapezunt every year. $^{4}$

Symptoms of poisoning occur after a dose dependent latent period of a few minutes to two or more hours. In severe intoxication, loss of coordination and progressive muscular weakness result. Atrioventricular and intraventricular conduction disturbances also may occur. Convulsions are reported occasionally. ${ }^{5}$

\section{CASE REPORTS}

The study is designed as a series of cases analysed retrospectively. Nineteen patients ( 12 men, seven women) aged between 22-61 years, were admitted to the emergency department with the symptoms of nausea, vomitting, hypotension, bradycardia, and fainting in the year 2002 (table 1). History was obtained from the patients except for four who had collapsed before admission. The relatives supplied the history in these four cases. Each patient ingested about 30 to 180 grams of honey several hours before admission. Fifteen of the patients had previously been diagnosed with a duodenal ulcer in the internal medicine or gastroenterology departments of the local hospitals. The reason for the honey ingestion may be the belief that honey heals a duodenal ulcer when consumed continuously. Initial physical examination showed that all patients had bradycardia and 15 had hypotension (arterial systolic blood pressure $<90 \mathrm{~mm} \mathrm{Hg}$ ). In four patients symptoms began suddenly while they were standing. These four patients sustained head trauma after falling due to possible sudden hypotension and collapse. Three patients had small (less than $5 \mathrm{~cm}$ in diameter) haematoma on their heads and neurological examinations were normal. One patient had a $6 \mathrm{~cm}$ cut on his head. He had cranial computed tomography (CT) for possible intracranial haemorrhage after a neurological consultation. The result was normal. In three patients symptoms were comparatively mild because of a slight decrease in blood pressure and sinus bradycardia. In two patients bradycardia was severe and four patients had complete AVB (fig lA).

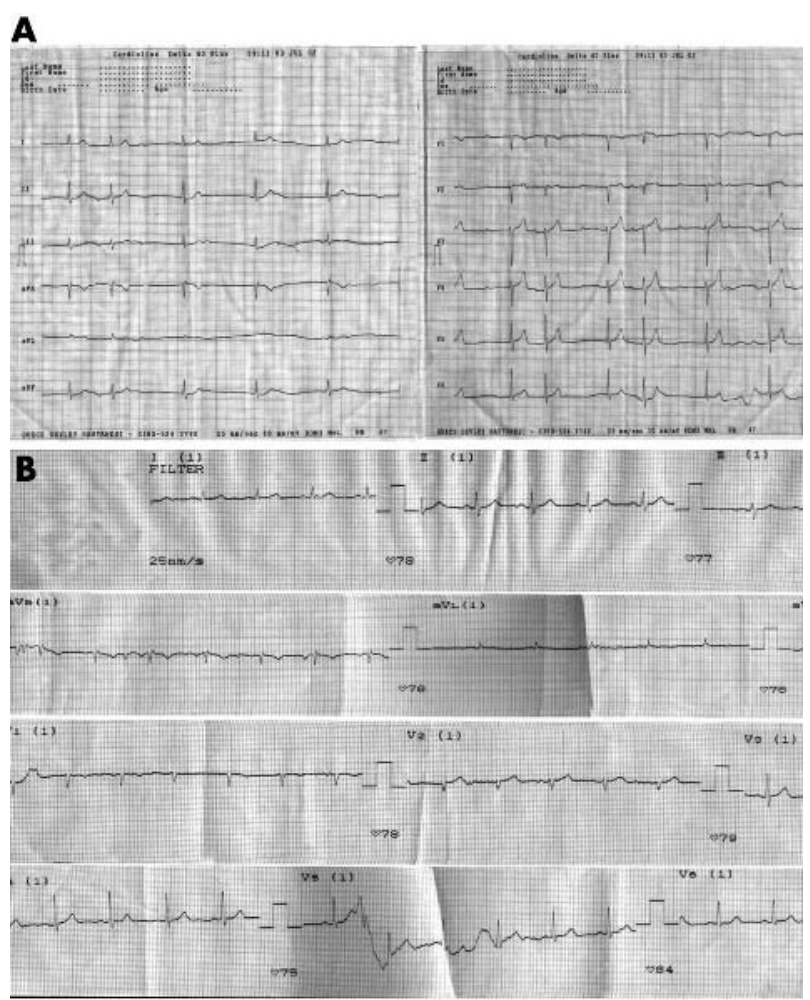

Figure 1 (A) Complete atrioventricular block in a patient after honey ingestion. (B) Sinus rhythm restored after $0.5 \mathrm{mg}$ atropine administration in the same patient. 


\begin{tabular}{|c|c|c|c|c|c|c|c|c|c|c|c|}
\hline $\begin{array}{l}\text { Patient } \\
\text { number }\end{array}$ & $\begin{array}{l}\text { Sex } \\
\text { (M/F) }\end{array}$ & $\begin{array}{l}\text { Age } \\
(y)\end{array}$ & $\begin{array}{l}\text { SBP } \\
(\mathrm{mm} \mathrm{Hg})\end{array}$ & $\begin{array}{l}\text { DBP } \\
(\mathrm{mm} \mathrm{Hg})\end{array}$ & $\begin{array}{l}\text { HR } \\
\text { (bpm) }\end{array}$ & ECG & $\begin{array}{l}\text { Amount } \\
\text { (g) }\end{array}$ & $\begin{array}{l}\text { PR } \\
\text { (ms) }\end{array}$ & $\begin{array}{l}\text { QT } \\
\text { (ms) }\end{array}$ & $\begin{array}{l}\text { QTc } \\
\text { (ms) }\end{array}$ & $\begin{array}{l}\text { Atropine } \\
\text { (mg) }\end{array}$ \\
\hline 1 & $M$ & 31 & 60 & 40 & 39 & $A \vee B$ & 180 & - & 410 & 330 & 1 \\
\hline 2 & $\mathrm{~F}$ & 22 & 95 & 65 & 48 & SB & 30 & 160 & 440 & 396 & - \\
\hline 3 & $M$ & 41 & 85 & 60 & 36 & SB & 50 & 200 & 380 & 294 & 0.5 \\
\hline 4 & $M$ & 46 & 70 & 30 & 34 & AVB & 120 & - & 460 & 348 & 1 \\
\hline 5 & $\mathrm{~F}$ & 44 & 80 & 60 & 46 & SB & 30 & 160 & 400 & 350 & 0.5 \\
\hline 6 & $M$ & 61 & 80 & 40 & 44 & SB & 30 & 200 & 380 & 333 & 0.5 \\
\hline 7 & $\mathrm{~F}$ & 32 & 90 & 50 & 42 & SB & 30 & 200 & 400 & 336 & - \\
\hline 8 & $M$ & 33 & 70 & 40 & 41 & SB & 60 & 120 & 430 & 358 & 1 \\
\hline 9 & $M$ & 46 & 75 & 45 & 49 & SB & 30 & 140 & 380 & 345 & 0.5 \\
\hline 10 & $\mathrm{~F}$ & 54 & 80 & 30 & 46 & SB & 40 & 120 & 420 & 368 & 0.5 \\
\hline 11 & $\mathrm{~F}$ & 51 & 75 & 40 & 38 & SB & 50 & 160 & 460 & 370 & 0.5 \\
\hline 12 & $M$ & 46 & 75 & 40 & 36 & AVB & 90 & - & 440 & 341 & 1 \\
\hline 13 & $M$ & 44 & 70 & 30 & 37 & AVB & 80 & - & 440 & 346 & 0.5 \\
\hline 14 & $\mathrm{~F}$ & 30 & 85 & 45 & 40 & SB & 40 & 180 & 380 & 330 & 0.5 \\
\hline 15 & $M$ & 24 & 60 & 40 & 39 & SB & 50 & 200 & 420 & 352 & 1 \\
\hline 16 & $\mathrm{~F}$ & 48 & 90 & 60 & 45 & SB & 30 & 160 & 360 & 313 & - \\
\hline 17 & $M$ & 42 & 80 & 50 & 47 & SB & 40 & 180 & 440 & 392 & 0.5 \\
\hline 18 & $M$ & 40 & 85 & 45 & 42 & SB & 50 & 160 & 400 & 336 & 0.5 \\
\hline 19 & M & 37 & 90 & 40 & 46 & SB & 30 & 200 & 440 & 385 & 0.5 \\
\hline $\begin{array}{l}\text { Mean } \\
\text { (SD) }\end{array}$ & $12 / 7$ & $\begin{array}{l}40 \\
(10)\end{array}$ & $\begin{array}{l}78 \\
(9)\end{array}$ & $\begin{array}{l}44 \\
(10)\end{array}$ & $\begin{array}{l}41 \\
\text { (4) }\end{array}$ & $4 / 15$ & $\begin{array}{l}55 \\
(38)\end{array}$ & $\begin{array}{l}180 \\
(30)\end{array}$ & $\begin{array}{l}414 \\
(29)\end{array}$ & $\begin{array}{l}332 \\
(76)\end{array}$ & \\
\hline
\end{tabular}

All patients were monitored in the coronary care unit for 24 hours. Sixteen patients received $0.5 \mathrm{mg}$ of atropin. Administration criteria were symptomatic hypotension and complete AVB. Two patients with symptomatic bradycardia and three patients with AVB were given a second dose of $0.5 \mathrm{mg}$ atropine five minutes after the initial dose because heart rate and blood pressure could not be restored (fig 1B). In all patients, heart rate and blood pressure returned to normal limits within two to nine hours. A basal rate of intravenous sodium chloride infusion $(100 \mathrm{cc} / \mathrm{h})$ was continued for 24 hours. The authors of the study do not recommend infusion of lager volumes of fluid for patients recovering from symptomatic hypotension because the main cause of hypotension in these patients are the underlying conduction disorders in which atropine is effective in most cases. All patients were discharged healthy the next day.

\section{DISCUSSION}

Grayanotoxins, mainly grayanotoxin I (andromedotoxin) occurs only in Ericaceae plants, are the compounds responsible for poisoning. They are extracted by bees from the leaves and flowers of rhododendron species. ${ }^{67}$ From the 18 forms of grayanotoxins, grayanotoxin I is responsible for honey poisoning. ${ }^{7}$ The grayanotoxins bind to sodium channels in cell membranes preventing inactivation and maintaining the cell in a state of depolarisation, during which entry of calcium into the cells may be facilitated.

The toxic effects of honey poisoning are bradycardia, cardiac arrhythmia, hypotension, nausea, vomiting, sweating, salivation, dizziness, weakness, loss of consciousness, fainting, blurred vision, chills, and cyanosis. A case of generalised convulsion has been reported in the literature. ${ }^{5}$ Cardiac disturbances are the main signs in this poisoning and Onat et al showed that atropine sulphate alleviated bradycardia attributable to grayanotoxin, and AF-DX 116, a selective M2-muscarinic receptor antagonist, restored heart rate. They suggested that M2-muscarinic receptors were involved in the cardiotoxicity of grayanotoxin. ${ }^{8}$
"Mad" honey is used in the Black Sea region as an alternative medicine for the treatment of gastric pains, bowel disorders, hypertension, and it is believed to be a sexual stimulant. ${ }^{1}$ The precise amount for a toxic dose is not known, but previously reported cases have suggested that "one teaspoonful" toxic honey may cause intoxication. ${ }^{1-5}$ In general the severity of the honey poisoning depends on the amount ingested. Our findings showed that as the amount ingested increases, the probability of development of AVB increases. However, this is just an observation. It should not be proposed that "mad honey" ingestion lower than $30 \mathrm{~g}$ is safe. The concentration of grayanotoxin ingested may differ greatly from case to case. As grayanotoxins are metabolised and excreted rapidly the patients generally regain consciousness and feel better within hours and heart rate and blood pressure usually return to normal within 24 hours. ${ }^{12}$

Because of the increasing preference for natural products, intoxication induced by consumption of honey will increase in the future especially with products bought directly from the beekeeper. Cases of honey intoxication should be considered in every country because of an increase in the consumption of imported, unprocessed honey. All people are believed to be susceptible. Honey poisoning should be kept in mind in previously healthy patients admitted with unexplained hypotension, bradycardia, and complete AVB. Inquiry should be made about the possibility of honey ingestion. Close surveillance and symptomatic treatment should be carried out and physicians should be alert for sudden worsening of bradycardia and progressive conduction disturbances.

\section{Authors' affiliations \\ H Özhan, Abant İzzet Baysal Üniversitesi Düzce Tıp Fakültesi, Kardiyoloji Kliniği Konuralp, Düzce, Turkey R Akdemir, M Yazici, H Gündüz, S Duran, C Uyan, Abant İzzet Baysal University Düzce Faculty of Medicine, Konuralp Düzce, Turkey}

Correspondence to: Dr H Özhan, Abant İzzet Baysal Üniversitesi Düzce Tıp Fakültesi, Kardiyoloji Kliniği Konuralp, Düzce, Turkey; ozhanhakan@yahoo.com

Accepted for publication 25 September 2003 


\section{REFERENCES}

1 Sutlupinar N, Mat A, Satganoglu Y. Poisoning by toxic honey in Turkey. Arch Toxicol 1993;67:148-50.

2 Von Malottki K. Wiechmann HW. Acute life-threatening bradycardia: food poisoning by Turkish wild honey. Dtsch Med Wochenschr 1996;121:936-8.

3 Gossinger H, Hruby K, Pohl A, et al. Poisoning with andromedotoxincontaining honey. Dtsch Med Wochenschr 1983;108:1555-8.

4 Geroulanos S, Attinger B, Cakmakci M. Honey-induced poisoning. Schweiz Rundsch Med Prax 1992;81:535-40.
5 Dilber $\mathbf{E}$, Kalyoncu M, Yarifi N, et al. A case of mad honey poisoning presenting with convulsion: intoxication instead of alternative therapy. Turk J Med Sci 2002;32:361-2.

6 Yavuz H, Özel A, Akkus I, et al. Honey poisoning in Turkey. Lancet 1991;337:789-90.

7 Hikino H, Ohizumi Y, Konino C, et al. Subchronic toxicity of Ericaceous toxins a rhododendron leaves. Chem Pharm Bull 1979;27:874-9.

8 Onat FY, Yegen BC, Lawrence R, et al. Mad honey poisoning in man and rat. Rev Environ Health 1991:9:3-9.

\title{
Atrial fibrillation after electrical shock: a case report and review
}

\author{
R Akdemir, H Gunduz, E Erbilen, I Ozer, S Albayrak, H Unlu, C Uyan
}

Emerg Med J 2004;21:744-746. doi: 10.1136/emj.2003.005496

A 52 year old man was admitted to an emergency department with a fast ventricular rate atrial fibrillation after an electrical shock. Electrical cardioversion was attempted after echocardiographic examination. This failed, but the heart rate slowed. Successful pharmacological cardioversion was achieved after 16 hours of amiodarone infusion. Preexcitation syndrome was detected on baseline echocardiograph. Serum cardiac specific markers were all within normal limits. No abnormal findings were detected by chest radiography, echocardiographic, or coronary angiographic investigations. Acute onset atrial fibrillation after electrical injury is discussed.

\footnotetext{
A
} 52 year old man was admitted to our emergency department with palpitation and shortness of breath after an electrical shock. He had touched a live cable carrying 220 volts during repair of a washing machine. He had lost consciousness for a while after the accident, but was conscious on admission. He had no history of cardiac disorder and there were no indications of coronary artery disease. On physical examination, his blood pressure was 90/70 mm Hg and his heart rate was about 220 beats per minute, with irregular rhythm. Lung examination revealed rales. The entry wounds were two contact abrasions located proximally on the second and third fingers of the right hand. The exit wound was a small burn injury on the right side of the tongue (fig lA).

Cardiac monitoring showed atrial fibrillation with faster ventricular conduction, permitting no time for ECG (The heart rate on the monitor of DC shock device was $220 \mathrm{bpm}$ ). He was given intravenous metoprolol $5 \mathrm{mg}$ three times over 30 minutes. We started heparin 1000 unit/h after an initial 5000 units intravenous bolus injection. Electrical cardioversion (300-360 J) was carried out three times in the emergency room after a normal echocardiographic examination. Successful cardioversion was not achieved, but ventricular conduction rate slowed to $120 \mathrm{bpm}$ on ECG (fig 1B). The patient was transferred to the coronary care unit for medical cardioversion and electrocardiographic monitoring. We started intravenous amiodarone infusion ( 1 g over $24 \mathrm{~h}$ ) after a $150 \mathrm{mg}$ intravenous bolus injection. By the 16th hour, normal sinus rhythm had been established with ventricular pre-excitation (Wolff-Parkinson-White syndrome)) (fig IC).

Cardiac specific enzymes (CK-MB, troponins) were all within normal limits in three successive measurements at 12 hours intervals. All other biochemical and haematological investigations were normal. Chest radiography was normal. Echocardiographic examination of cardiac structures was normal. Coronary artery disease was excluded by coronary angiography. The patient rejected electrophysiogical study and catheter ablation. We treated the patient with acetylsalicylate acid $300 \mathrm{mg} /$ day for two months and he has no further complaints.

\section{DISCUSSION}

Domestic electrical supplies operate at 220-240 volts, and alternating current is more dangerous than direct current. Electrical shocks generally result from contact with live wires or lightning. Cardiovascular effects include myocardial infarction, transient accelerated hypertension, left ventricular dysfunction, cardiac rupture, and arrhythmias. ${ }^{1-3}$ Premature ventricular contractions, ventricular tachycardia, ventricular fibrillation, atrial tachicardia, atrial fibrillation, bundle branch, and complete heart block may be occur after electrical shock. ${ }^{3-4}$ Follow up studies show that the prevalence of arrhythmias after electrical injury varies between $10 \%$ to $36 \%$. Atrial fibrillation after electrical shock is extremely rare. In a study of 182 cases of electrical injury over a 20 year period, only two instances of atrial fibrillation were reported and one of them required cardioversion. $^{25}$

The mechanism of electrical current induced arrhythmias is not clear. Because of differences in electrical resistance, current travels preferentially along blood vessels and nerves, making the heart most susceptible to injury. ${ }^{5}$ Patchy necrosis can be seen in heart muscle biopsy specimens after electrical injuries, the fibrotic tissue being a potential chronic arrhythmogenic focus. ${ }^{5}$ Increased cardiac sodium/potassium pump activities and an increase in potassium concentration have also been described. ${ }^{6}$ Cardiac arrhythmias may occur at the time of electrical shock or later, but mostly within first day after injury. ${ }^{6}{ }^{7}$

Arrowsmith et al retrospectively evaluated 145 patients with electical injury in the same centre over the five year period; $128(88 \%)$ had suffered low voltage injury and 17 $(12 \%)$ had suffered high voltage injuries $(>1000 \mathrm{~V})$. The 


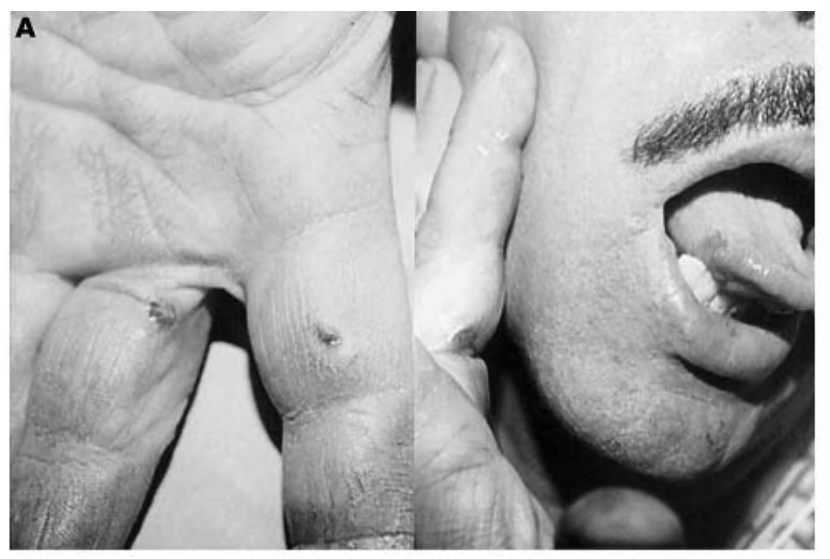

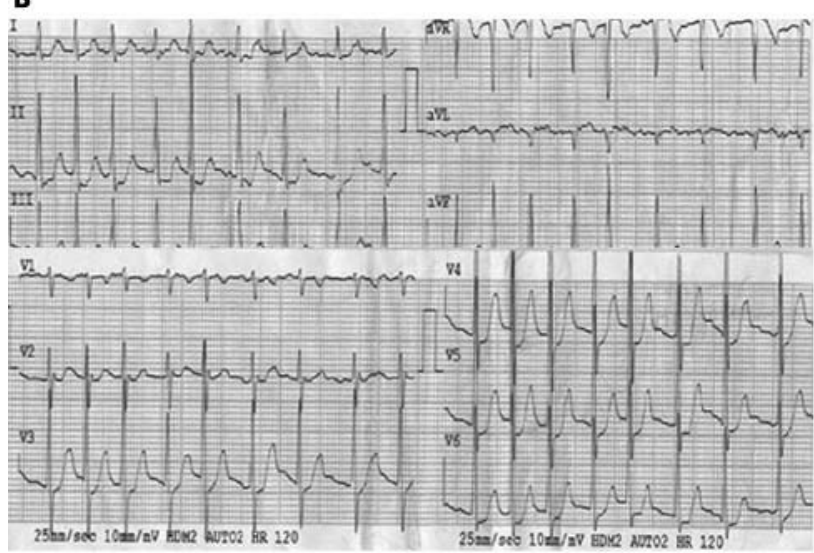

c

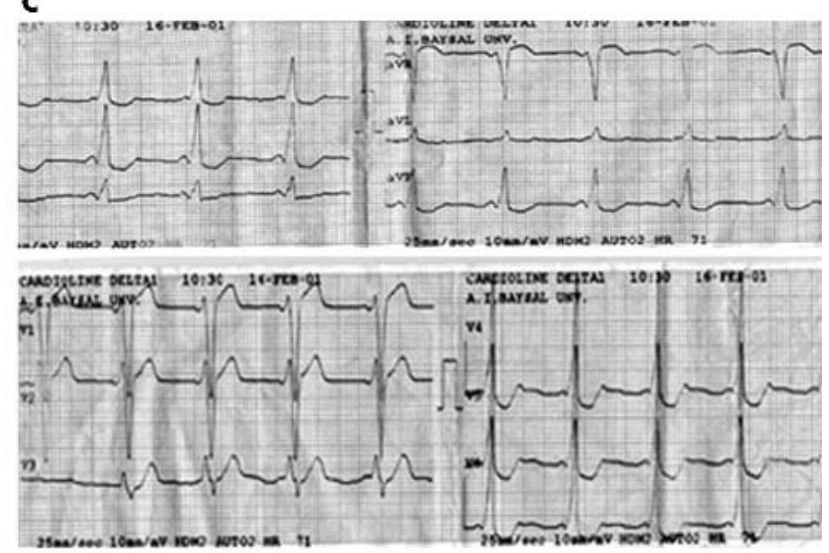

Figure 1 (A) The entry and exit burn injuries attributable to electrical shock located in the proximal portions of the second and third fingers of the right hand and on the right side of the tongue. (B) Atrial fibrillation with fast ventricular rate after electrical shock. (C) ECG of the patient with pre-exitation syndrome after cardioversion.

frequency of cardiac complications was 3\% (four patients). Atrial fibrillation was detected in only one patient in this study and in this case normal sinus rhythm was restored after intravenous digoxin infusion. Purdue et al ${ }^{8}$ recommended cardiac monitoring of patients with electrical injury if there was loss of consciousness, recorded arrhythmia in the field, abnormal ECG on admission, and rhythm disturbance during monitoring in the emergency room.

There were three small entry and exit burn injuries attributable to low voltage electrical shock in our patient but he had lost his consciousness for a while after the accident. However, he was conscious but his blood pressure was below normal on admission. A narrow QRS atrial fibrillation with a fast ventricular rate had been detected by ECG in the emergency room. Because it had been an acute onset atrial fibrillation, we attempted electrical cardioversion after injection of a 5000 unit heparin bolus and echocardiographic evaluation. But electrical cardioversion was unsuccessful for three times with 200-300 and 360 joules respectively and we carried out medical cardioversion by intravenous amiodarone infusion and restored the sinus rhythm. We noticed pre-excitation syndrome after cardioversion. ${ }^{9}$ Almost all patients with atrial fibrillation described in previous reports had severe electrical burns after high voltage injuries $(>1000 \mathrm{~V})$. In contrast, our patient had suffered a low voltage electrical shock with two small burn injuries that required no additional treatment.

We maintained cardiac monitoring in the coronary care unit, as previously suggested, and restored sinus rhythm by intraneous amiodarone infusion. After 16 hours, we noted ventricular pre-excitation on the patient's ECG. Other causes of arrhythmia were excluded. There were no abnormal findings detected by echocardiography and coronary angiography. We have planned electrophysiological study, but he refused further investigation and invasive treatment. In conclusion, electrical shocks with low voltage may cause atrial fibrillation among other severe cardiac dysfunctions. Most atrial fibrillations after electrical shocks are self limiting, but the presence of pre-excitation syndrome requires aggressive treatment.

\section{Authors' affiliations}

R Akdemir, E Erbilen, I Ozer, S Albayrak, H Unlu, Abant Izzet Baysal University, Düzce Medical School, Department of Cardiology, Düzce, Turkey

H Gunduz, C Uyan, Abant Izzet Baysal University, Izzet Baysal Medical School, Department of Cardiology, Düzce, Turkey

Correspondence to: Dr R Akdemir, Abant Izzet Baysal University, Duzce Medical School, Deapartment of Cardiology, Konuralp/Duzce, Turkey; ramazanakdemir@hotmail.com

Accepted for publication 28 March 2003

\section{REFERENCES}

1 Divincenti FC, Moncrief JA, Pruit BA Jr. Electrical injuries. a review of 65 cases. J Tauma 1969;9:497-507.

2 Butler ED, Gant TD. Electrical injuries, with special reference to the upper extremities. A review of 182 cases. Am J Surg 1977;134:95-101.

3 Solem L, Fischer RP, Strate RG. The natural history of electric injury. J Trauma 1977;17:487-92. 
4 Wander GS, Bansal RK, Anand IS, et al. Atrial ibrillation following electrical injury. Jpn Heart J 1992;33:131-4.

5 Boggild $\mathbf{H}$, Freund L, Bagger JP. Persistent atrial fibrillation following electrical injury. Occup Med 1995;45:49-50.

6 Jensen PJ, Thomsen PE, Bagger JP, et al. Electrical injury causing ventricular arrhythmias. Br Heart J 1987;57:279-83.
7 Arrowsmith J, Usgaocar RP, Dickson WA. Electrical injury and the frequency of cardiac complications. Burns 1997;23:576-8.

8 Purdue GF, Hunt JL. Electrocardiographic monitoring after electrical injury: necessity or luxury? J Trauma 1986;26:166-7.

9 Wellens $\mathrm{HJ}$, Lie KI, Bar FW, et al. Effect of miodarone in the Wolff-ParkinsonWhite syndrome. Am J Cardiol 1976;38:189-94.

\section{Postnatal pre-cordial pain. Pulmonary embolism or peripartum cardiomyopathy}

\section{B Quinn, B Doyle, J Mclnerney}

Emerg Med J 2004;21:746-747. doi: 10.1136/emj.2003.005132

$\mathrm{P}$ atients who attend the emergency department with precordial pain after pregnancy present a diagnostic dilemma. While pulmonary embolism (PE) is a comparatively common cause, ${ }^{1}$ peripartum cardiomyopathy (PPCM) although rare, should always be considered in the differential diagnosis. ${ }^{2}$ PPCM is a rare form of congestive heart failure that affects women late in pregnancy or in the early peurperium. ${ }^{3}$ It is a disorder of unknown aetiology with a high mortality rate approaching $50 \% .^{3-5}$ We report a presentation of a patient with postnatal pre-cordial pain and the clinical findings, which permitted correct diagnosis and treatment.

\section{CASE REPORT}

A 36 year old white woman was referred to the emergency department by her general practitioner with a diagnosis of suspected PE. She had had a caesarean section seven days previously, with a three day history of exertional precordial discomfort, dyspnoea on exertion, and right calf swelling. There was no productive cough or haemoptysis. She had no personal or family history of cardiac disease. She smoked five cigarettes a day before becoming pregnant but denied smoking since. She had no history suggestive of a preexisting heart condition as she had a previous excellent exercise tolerance.

On examination she was pale and anxious with a respiratory rate of 20 breaths per minute and a heart rate of 110 beats per minute and regular. Blood pressure was 140/ 80. Bilateral coarse crepitations and a gallop rhythm were heard on auscultation of her chest. On lower limb examination she had bilateral ankle oedema, which was more pronounced on the right. The right calf was also tender.

Initial impression was of congestive cardiac failure or a pulmonary embolism secondary to a right lower limb DVT.

An ECG showed left axis deviation with left bundle branch block. A chest radiograph showed pulmonary oedema and an increased cardiothoracic ratio (fig 1).

Treatment included high flow oxygen via non-rebreather mask, intravenous diuretic (frusemide $80 \mathrm{mg}$ ), and a therapeutic dose of a low molecular weight heparin. An echocardiogram was immediately performed that showed a dilated left ventricle with an ejection fraction of $20 \%$. The patient was admitted to the coronary care unit and an ACE inhibitor (captopril) was added to her treatment. A left and right heart catheterisation was performed later the same day, which showed normal coronary arteries and a raised right heart and pulmonary artery pressures. V/Q scan was undertaken at day 3 and showed low probability of pulmonary embolus.

The patient made good recovery over the next five days and was discharged from hospital six days later receiving treatment with a $\beta$ blocker, ACE inhibitor, and a diuretic.

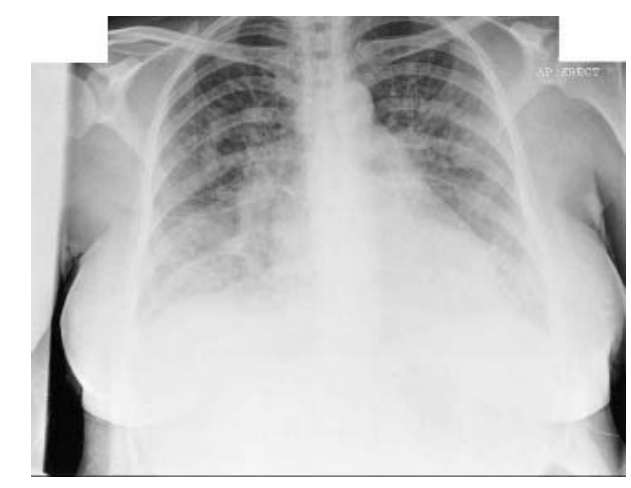

Figure 1 Chest radiograph showing pulmonary oedema and an increased cardiothoracic ratio.

\section{DISCUSSION}

While pulmonary embolism was suspected in the differential diagnosis the symptoms of exercise related chest pain, exertional dyspnoea, and orthopnea pointed to a primary cardiac pathology. The clinical signs of pulmonary oedema and gallop rhythm also pointed away from a thromboembolic cause. While the patient had raised D-dimers (commonplace in pregnancy), and positive risk factors on thromboembolic risk stratification, urgent echocardiography permitted prompt and correct diagnosis of PPCM.

PPCM is defined on the basis of four criteria. ${ }^{3}$

- Development of cardiac failure in the last month of pregnancy or within five months of delivery.

- Absence of an identifiable cause for the cardiac failure.

- Absence of recognisable heart disease before the last month of pregnancy.

- Left ventricular systolic dysfunction shown on echocardiograph.

The incidence of PPCM is unknown. An accepted incidence is 1 per $3000-4000$ live births per year. ${ }^{6}$ The incidence is highest in some areas of Nigeria. ${ }^{7}$ The cause of PPCM remains unknown, however a number of potential risk factors have been proposed.

- Age greater than 30 years ${ }^{3}$

- Multiparity

- Women of African descent ${ }^{8}$

- Pregnancy with multiple fetuses ${ }^{9}$

Abbreviations: PPCM, peripartum cardiomyopathy; PE, pulmonary embolism 
- A history of pre-eclampsia, eclampsia, or postpartum hypertension

- Maternal cocaine misuse ${ }^{10}$

Patients with PPCM most commonly present with dyspnoea but other frequent complaints include cough, orthopnoea, paroxysmal nocturnal dyspnoea, haemoptysis, and chest discomfort. ${ }^{3}$

ECG findings may include sinus tachycardia, non-specific ST and T wave abnormalities, and voltage abnormalities. The chest radiograph typically shows enlargement of the cardiac silhouette with evidence of pulmonary venous congestion or interstitial oedema, or both. An echocardiogram needs to be performed in all patients suspected of having PPCM. It usually shows left ventricular enlargement and significant global reduction in ejection fraction. Other findings may include left atrial enlargement, mitral and tricuspid regurgitation, and a small pericardial effusion. ${ }^{11}$

Treatment of PPCM is similar to that for other types of congestive cardiac failure. However, the adverse effects of these agents on the fetus or breast feeding infant must be borne in mind. Diuretics may be used prepartum although hyponatraemia has been reported in infants born to mothers taking diuretics. Angiotensin converting enzyme inhibitors are absolutely contraindicated prepartum, when they may be associated with adverse fetal renal effects and an increase in neonatal mortality. $\beta$ blockers are generally safe in pregnancy. ${ }^{4}$

Mortality estimates for patients with PPCM range from $25 \%$ to $50 \%$ with most deaths occurring within the first three months postpartum. ${ }^{3-5}$ Death is usually caused by progressive pump failure, arrhythmias, or thromboembolic events. ${ }^{12}$

The general consensus among experts is that patients with PPCM and persistent left ventricular dysfunction, are at extremely high risk of complications and death with subsequent pregnancies. ${ }^{13}$ Therefore these patients should be advised to avoid pregnancy. Even in patients where left ventricular function recovers, there seems to be some risk for recurrence. ${ }^{13}$ They need to be counselled about the potential risks before pregnancy and be carefully monitored if they choose to become pregnant again.

While rare, the diagnosis of PPCM needs a high index of suspicion, good history taking, attention to abnormal clinical signs, and rapid echocardiography. Echocardiography is a useful tool in diagnosis of both cardiac and trauma emergencies within the emergency department. ${ }^{14}$ Delay in diagnosis of PPCM or erroneous diagnosis of "PE" results in poor outcome. ${ }^{2}$

\section{CONTRIBUTORS}

Barry Quinn did the literature review and wrote the paper. Brendan Doyle assisted with interpretation of the cardiac investigations. John McInerney made amendments to the original draft of the case report and acts as guarantor.

\section{Authors' affiliations}

B Quinn, J Mclnerney, Emergency Department, Mater Misericordiae Hospital, Dublin, Ireland

B Doyle, Cardiology Department, Mater Misericordiae Hospital

Correspondence to: Mr J J Mclnerney, Emergency Department, Mater Misericordiae Hospital, Dublin D7, Ireland; jmcinerney@mater.ie

Accepted for publication 14 July 2003

\section{REFERENCES}

1 Armour R, Schwelder M, Kerstein MD. Current assessment of thromboembolic disease and pregnancy. Am Surg 200;67:641-4.

2 Lasinska-Kowara M, Dudziak M, Suchorzewska J. Two cases of postpartum cardiomyopathy initially misdiagnosed for pulmonary embolism. Can J Anaesth 2001;48:773-7.

3 Demakis JG, Rahimtoola SH, Sutton GC, et al. Natural course of peripartum cardiomyopathy. Circulation 1971;44:1053-61.

4 Sliwa K, Skudicky D, Bergemann A, et al. Peripartum cardiomyopathy: analysis of clinical outcome, left ventricular function, plasma levels of cytokines and Fas/APO-1. J Am Coll Cardiol 2000;35:701-5.

5 Costanzo-Nordin MR, O'Connell JB. Peripartum cardiomyopathy in the 1980s: Etiologic and prognostic considerations and review of the literature. Prog Cardiol 1989;2:225

6 Pearson GD, Veille JC, Rahimtoola S, et al. Peripartum cardiomyopathy: National Heart, lung, and Blood Institute and Office of Rare Diseases workshop recommendations and review. JAMA 2000;283:1 183-8.

7 Fillmore SJ, Parry EO. The evolution of peripartal heart failure in Zaria. Circulation 1977;56:1058-6.

8 Veille JC. Peripartum cardiomyopathies: a review. Am J Obstet Gynecol 1984;148:805-18.

9 Homans DC. Peripartum cardiomyopathy. N Engl J Med 1985;312:1432-7.

10 Mendelson MA, Chandler J. Postpartum cardiomyopathy associated with maternal cocaine abuse. Am J Cardiol 1992;70:1092-4.

11 Lampert MB, Lang RM. Peripartum cardiomyopathy. Am Heart J 1995; 130:860-70.

12 Felker CM, Jaeger CJ, Klodas E, et al. Myocarditis and longterm survival in peripartum cardiomyopathy. Am Heart J 2000;140:785.

13 Elkayam U, Tummala PP, Rao K, et al. Maternal and fetal outcomes of subsequent pregnancies in women with peripartum cardiomyopathy. N Engl J Med 2001;344:1567-71.

14 Mayron R, Gaudio FE, Plummer D, et al. Echocardiography performed by emergency physicians: impact on diagnosis and therapy. Ann Emerg Med 1998;17:150-4.

\section{Hard to swallow: an unusual complication of thrombolysis} G C Price, A P Kulkarni, M Saxena, M O'Leary

$\mathrm{T}$ hrombolysis for acute myocardial infarction always has a risk of causing haemorrhage. ${ }^{1}$ Both gastro-oesophageal reflux disease and ischaemic heart disease are common, ${ }^{2}$ and can have some overlap in their symptomatology. We present a patient who suffered an unusual complication of thrombolytic therapy.

\section{CASE REPORT}

An 80 year old man presented to his local emergency department with an acute inferior myocardial infarction. His only history of note was quadruple coronary artery bypass grafting at the age of 70, from which he had made a good recovery. He was assessed as appropriate for thrombolysis; tenectplase $37.5 \mathrm{mg}$, and aspirin $300 \mathrm{mg}$ were given, and systemic heparinisation started. His electrocardiographic changes of myocardial infarction improved and reperfusion was thought to have occurred. An echocardiogram at 24 hours after admission reported moderate systolic dysfunction with infero-posterior akinesis, consistent with recent infarction. His troponin I concentrations were $0.64 \mu \mathrm{g} / \mathrm{l}$, $14.1 \mu \mathrm{g} / \mathrm{l}$, and $21.6 \mu \mathrm{g} / \mathrm{l}$ (normal range $0-0.1 \mu \mathrm{g} / \mathrm{l}$ ) at 6,12 , and 24 hours after admission respectively. He was given 


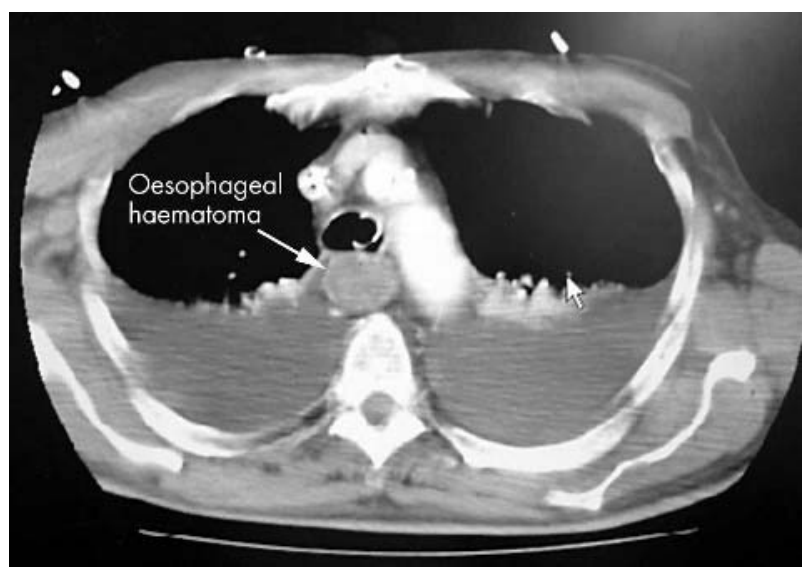

Figure 1 Contrast computed tomogram of the thorax showing a large submucosal oesophageal haematoma.

regular $\beta$ blockers, aspirin, and statin therapy, and remained well for the next 36 hours. He then complained of severe, sudden onset chest pain, which was associated with a small amount of haemoptysis and dysphagia. The chest pain was unrelieved by nitrates, and he complained of increasing difficulty with swallowing. This symptom was initially dismissed and thought to be a manifestation of the distress caused by his severe chest pain. His electrocardiogram at this time showed non-specific ST segment changes, which were considered suggestive of myocardial ischaemia. He was considered again for thrombolysis as it was felt that the most probable diagnosis was re-infarction. However, because of the non-specific ST segment changes he fortuitously underwent another trans-thoracic echocardiogram. This showed external compression of his left atrium, but no new wall motion abnormalities. A contrast computed tomogram of his thorax showed a large submucosal oesophageal haematoma (fig 1).

Thrombolysis was deferred, heparinisation stopped, and coagulation normalised with protamine sulphate and fresh frozen plasma.

He became increasingly agitated and confused and required intubation and ventilation. He was transferred to our hospital for further treatment.

We elected to keep the patient sedated, intubated, and ventilated and $\beta$ block was continued intravenously. An upper gastrointestinal surgical opinion was obtained and it was decided to treat him expectantly.

He was kept sedated and ventilated for a further 48 hours, to allow good conditions for myocardial oxygenation and to reduce the likelihood of further oesophageal bleeding from retching or vomiting. He was extubated without incident at 72 hours after admission. He was initially parenterally fed and then permitted oral feed on day six of his admission to our hospital, when he was able to swallow his own saliva. Serial CT scans of the submucosal haemorrhage showed gradual resolution over the course of two weeks. He unfortunately suffered a cardiac arrest secondary to ventricular fibrillation on day 17 of his admission while awaiting coronary angiography. Cardiopulmonary resuscitation was unsuccessful.

\section{DISCUSSION}

Thrombolytic therapy has become an important advance in the treatment of acute myocardial infarction. ${ }^{3}$ There is evidence that the sooner that reperfusion is achieved the better the outcome is for the patient, and so it has become standard practice to try to administer thrombolysis in eligible patients as soon as possible. ${ }^{4}$
The clinical questions that are asked before thrombolysis are chosen to ascertain the risk of catastrophic haemorrhage. Major bleeding from thrombolytic treatment may occur in up to $4 \%$ of patients undergoing thrombolysis for acute myocardial infarction. ${ }^{5}$ The incidence of bleeding in the 96 hour period after thrombolysis for acute myocardial infarction with either streptokinase or recombinant tissue plasminogen activator has been studied. Bleeding occurred in 3.8\% of thrombolysed patients overall. The leading types of bleeding of all patients affected were: perivascular access site $(18.4 \%)$, gastrointestinal $(6.4 \% \mathrm{t})$, skin/soft tissue/muscle $(5.0 \%)$, urinary $(3.4 \%)$, pulmonary $(2.2 \%)$, systemic $(1.9 \%)$, and oral $(1.4 \%){ }^{6}$

The recombinant tissue factor plasminogen activator, tenecteplase was given to our patient. It is reported to have fewer major bleeding complications when compared with alteplase, and is simpler to administer as it is given as a once only bolus dose. ${ }^{7}$ For these reasons it has been promoted as the ideal agent for prehospital thrombolysis. ${ }^{8}$ The half life of tenecteplase is 90 to 120 minutes, so it is not clear as to whether this was the cause of his oesophageal haematoma, or whether it was attributable to the heparinisation and aspirin therapy.

It is also well described that the symptoms of myocardial infarction can be mimicked by gastro-oesophageal reflux disease, ${ }^{9}$ and indeed the two conditions can often coexist within the same patient, in part because smoking is strongly associated with both conditions. ${ }^{10}{ }^{11}$ What is perhaps not as well recognised is that other oesophageal abnormalities, in particular oesophageal rupture, can also present in a similar way to myocardial infarction. ${ }^{12}$ The unusual development of a submucosal haematoma in our patient did lead to similar diagnostic confusion, particularly in the context of a recent acute myocardial infarction. It was fortunate that our patient had an echocardiogram, which gave an important clue to the cause of his dysphagia, for had further thrombolysis been given at this time, the immediate outcome would have been disastrous. It pays to listen to the patient, especially if they are complaining of unusual symptoms in the face of recent thrombolytic therapy.

\section{Authors' affiliations}

G C Price, A P Kulkarni, M Saxena, M O'Leary, Intensive Care Unit, St George Hospital, Sydney, Australia

Correspondence to: Dr G C Price, Intensive Care Unit, St George Hospital, Gray Street, Kogarah, Sydney, Australia;

grantcprice@hotmail.com

Accepted for publication 8 September 2003

\section{REFERENCES}

1 Califf RM, Fortin DF, Tenaglia AN, et al. Clinical risks of thrombolytic therapy. Am J Cardiol 1992;69:12-20A.

2 Castell DO. Chest pain of undetermined origin: overview of pathophysiology. Am J Med 1992;92:2-4S

3 ISIS-2 Collaborative group. Randomized trial of intravenous streptokinase, oral aspirin, both or neither among 17,187 cases of suspected acute myocardial infarction. Lancet 1988;ii:349-60.

4 Lip GYH, Chin BSP, Prasad N. Antithrombotic therapy in myocardial infarction and stable angina. BMJ 2002;325:1287-9.

5 Berkowitz SD, Granger CB, Pieper KS, et al. Incidence and predictors of bleeding after contemporary thrombolytic therapy for myocardial infarction. Circulation 1997;95:2508-16.

6 McLeod DC, Coln WG, Thayer, et al. Pharmacoepidemiology of bleeding events after the use of $r$-alteplase or streptokinase in acute myocardial infarction. Ann Pharmacother 1993;27:956-92.

7 ASSENT 2 Investigators. Single-bolus tenecteplase compared with frontloaded alteplase in acute myocardial infarction: the ASSENT-2 double-blind randomised trial, Assessment of the Safety and Efficacy of a New Thrombolytic Investigators. Lancet 1999;354:716-22.

8 Pedley DK, Bissett K, Conolly EM, et al. Prospective observational cohort study of time saved by prehospital thrombolysis for ST elevation myocardial infarction delivered by paramedics. BMJ 2003;327:22-6. 
9 Demeester TR, O'Sullivan GC, Bermudez B, et al. Esophageal function in patients with angina-type chest pain and normal coronary angiograms. Ann Surg 1982; 196:488-97.

10 Bottcher M, Falk E. Pathology of the coronary arteries in smokers and nonsmokers. J Cardiovasc Risk 1999;6:299-302.
11 Isolauri J, Laippala P. Prevalence of symptoms suggestive of gastro-oesophageal reflux disease in an adult population. Ann Med 1995;27:67-70.

12 Nehra D, Beynon J, Pye JK. Spontaneous rupture of the oesophagus (Boerhaaves syndrome). Postgrad Med J 1993;69:214-16.

\title{
Congenital para-oesophageal hiatus hernia: an interesting family history
}

\author{
J E Rees, S Robertson, A W McNinch
}

Emerg Med J 2004;21:749-750. doi: 10.1136/emj.2003.007310

Ir rue congenital para-oesophageal hiatus hernias are rare'; an intrathoracic gastric volvulus complicating such a hernia is rarer still although a well recognised paediatric surgical emergency. Rapid diagnosis and treatment is required to avoid gastric gangrene, perforation, or dilatation that can lead to cardiopulmonary arrest. ${ }^{2}$

\section{CASE REPORT}

A girl of 18 months presented to the emergency department in a collapsed state having vomited all liquids taken for 48 hours. The vomit was dark, stained with blood but not with bile, and was foul smelling. She had been irritable throughout the episode with obvious borborigmia and had not had a wet nappy for 24 hours.

Similar episodes of foul vomiting had occurred about every two weeks for the previous six months, each episode lasting four to five days before resolving spontaneously. During each episode the child was irritable, lethargic, passed less urine, and opened her bowels less frequently. No abdominal pain was apparent. There was no blood or mucus in her stools. She had presented to her general practitioner with each episode and had been given a diagnosis of gastroenteritis on a number of occasions. As each episode had resolved spontaneously further investigations were not arranged.

There was no relevant past history and developmental progress was normal. It was noted that a maternal aunt had died at the age of 2 weeks of a "diaphragmatic hernia".

On examination the girl was drowsy, responding to pain but not to voice, and floppy with dark vomit stains around her face. Her breath was offensive and ketotic. She was clinically dehydrated with a capillary refill time of three to four seconds. Her abdomen was soft and non-tender; the epigastrium was mildly distended with increased bowel sounds and a succussion splash. The respiratory rate was 30 breaths/minute without any distress and breath sounds were normal.

The working diagnosis at this stage was a midgut volvulus secondary to malrotation.

Laboratory results included venous $\mathrm{pH} 7.3$, bicarbonate $16 \mathrm{mmol} / \mathrm{l}$, base excess -0 , urea $9.1 \mathrm{mmol} / \mathrm{l}$, and "bedside" glucose $3.5 \mathrm{mmol} / \mathrm{l}$. White blood cell count of $10.5 \times 10^{9} / 1$ with a neutrophil count of $5.3 \times 10^{9} / \mathrm{l}$, and $\mathrm{C}$ reactve protein $<3 \mathrm{mg} / \mathrm{l}$. There was a good clinical response to bolus $0.9 \%$ saline $20 \mathrm{ml} / \mathrm{kg}$, which was followed by generous maintenance fluids $(8.5 \mathrm{ml} / \mathrm{kg} / \mathrm{h})$.

A nasogastric tube drained only $10 \mathrm{ml}$ of bloodstained fluid; oral fluids were withheld.

Chest and abdominal radiographs showed a large gastric air bubble extending across the midline from the left up into the right chest. A lateral chest radiograph showed the prominent gastric air-fluid level seen to lie posteriorly (fig l).
Given the history, clinical findings, and metabolic acidosis an obstructed intrathoracic gastric volvulus with compromise of the gastric blood supply seemed likely. Once stable the child was transferred immediately to a centre with specialist paediatric surgeons.

At surgery that night she was found to have an obstructed congenital para-oesphageal hiatus hernia, with the whole stomach in the chest. The hernia was reduced and the defect repaired. Five days postoperatively she developed an intussusception requiring further surgery but her recovery was uneventful thereafter. She was discharged home 14 days after presentation.

\section{DISCUSSION}

Five per cent of hiatus hernias are para-oesophageal but the vast majority are believed to be acquired rather than truly congenital. They involve the greater curvature of the stomach or, very rarely, the whole stomach ascending into a preformed sac within the mediastinum. ${ }^{3}$

Most congenital para-oesophageal hiatus hernias occur sporadically but there are about 20 case reports of familial paraoesophageal hernias, including a report of two affected siblings. ${ }^{4}$

Congenital paraoesophageal hiatus hernias present in a number of ways including failure to thrive, epigastric distension with projectile vomiting especially after meals, symptoms of obstruction, collapse, and cardiopulmonary arrest. $^{2}$

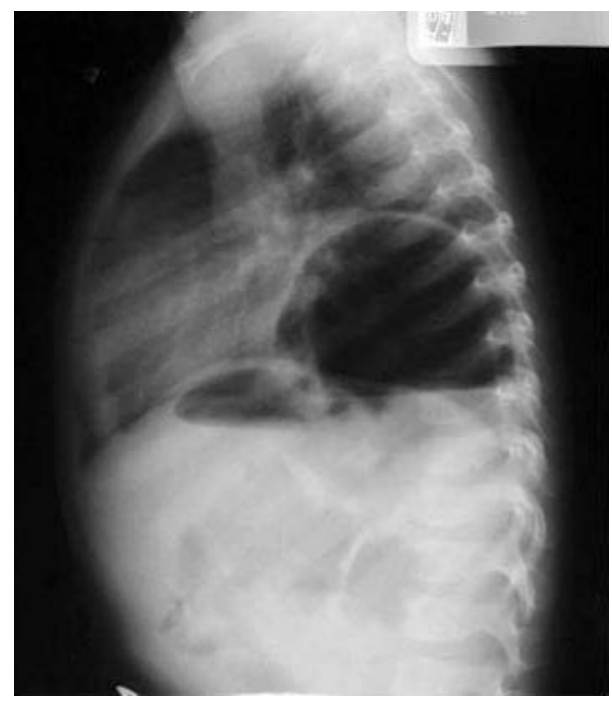

Figure 1 Lateral chest radiograph showing air fluid levels in the stomach. 
Volvulus of the intrathoracic stomach can precipitate partial or complete obstruction of the stomach, strangulation, and perforation. Acute gastric dilatation can directly impede venous return and cardiac output. Clinical deterioration can be rapid unless halted by rapid resuscitation and urgent surgical correction. After resuscitation plain antero-posterior and lateral radiographs, augmented with contrast studies if necessary, should confirm the diagnosis.

In a solely breast fed infant blood clotting should be checked and vitamin $\mathrm{K}$ given if indicated.

Suspicion is the key to successful management. If the presentation is acute there is a high likelihood of volvulus, obstruction, and/or gastric dilatation, and so fluid resuscitation will be required and oral fluids should be withheld. Ideally a nasogastric tube should be passed to attempt deflation of the stomach but if there is a complete gastric volvulus this is unlikely to be successful. The child should then be transferred, without delay, to a specialist centre for surgery to reduce the hernia and repair the defect.

\section{ACKNOWLEDGEMENTS}

We thank Miss Cusick, Consultant Paediatric Surgeon, The Bristol Royal Hospital for Children who advised on the management of this child before transfer, performed the surgery, and reviewed this paper.

\section{CONTRIBUTORS}

Jacqui Rees, Simon Robertson, and Andrew McNinch all attended the patient. The paper was written by Jacqui Rees who acts as guarantor for the content; the other authors reviewed and advised on the paper.

\section{Authors' affiliations}

J E Rees, S Robertson, A W McNinch, Department of Paediatrics, Royal Devon and Exeter Hospital, Exeter, Devon, UK

Correspondence to: Miss J E Rees, Department of Paediatrics, c/o Bramble Ward, Royal Devon and Exeter Hospital, Wonford Site, Bovemoor's Lane, Exeter, Devon EX2 5DF, UK; jakrees@doctors.org.uk

Accepted for publication 27 June 2003

\section{REFERENCES}

1 Jewad AJ, al-Samarrai Al, al-Mofada S, et al. Congenital para-oesophageal hiatus hernia in infancy. Pediatr Surg Int 1998;13:91-4.

2 al-Salem AH. Intrathoracic gastric volvulus in infancy. Pediatr Radiol 2000;30:842-5.

3 Mann CV, Williams NS, Russell E, eds. Bailey and Love's short practice of surgery. 22nd ed. London: Chapman and Hall, 1995:654-55.

4 Baglaj SM, Noblett HR. Paraoesophageal hernia in children: familial occurance and review of the literature. Pediatr Surg Int 1999;15:85-7.

\section{Lightning: an unusual cause of cerebellar infarction S Aslan, S Yilmaz, O Karcioglu}

The neurological complications of lightning injury are not infrequent. However, scarce data are available on cerebellar infarction attributable to lightning injury. A 45 year old man was admitted to the emergency department because of lightning injury. The patient had a Glasgow coma scale score of $13 / 15$ on arrival at hospital with accompanying dysarthria and hypotonia. Computed tomography of the head showed only a mild cerebral oedema. Ataxia was recorded on the fourth day. Magnetic resonance imaging of the head showed ischaemia predominantly in the cerebellar hemispheres bilaterally and in the parietal, temporal, and frontal lobes on the right. Anti-oedema treatment was started. The patient was discharged after seven days. After one month the patient was re-examined and found to have minimal ataxia and dysarthria. Lightning injury should not be overlooked in the aetiology and differential diagnosis of acute cerebellar ischaemic insult and relevant clinical findings in adults.

ightning injury is one of the most frequent injuries by natural phenomenon and often results in a high - mortality, ranging from $20 \%$ to $30 \%$. The most vulnerable subjects to lightning injuries are those who work in the open fields. ${ }^{1}$

Although lightning injuries may involve all organ systems, injuries to the cardiovascular system and central nervous system (CNS) are the most common. Burns, tinnitus, blindness, and secondary blunt trauma are also reported. Most victims have associated multisystem involvement. ${ }^{2}$

Several case reports have presented various neurological complications caused by lightning injury. On the other hand, no report related to cerebellar infarction caused by lightning injury was identified.

\section{CASE REPORT}

A 45 year old male farmer was admitted to the university based emergency department on a summer night with burns on his face, right gluteal and lumbar regions, and changed mental status after being struck by lightning in his farm. The patient was brought to the hospital about nine hours after the strike, and Glasgow coma scale (GCS) score was recorded as 13/15 (E3, M6, V4). Second degree burns (about 7\%, calculated via the rule of a palm size $=1 \%$ ) were found scattered on the right forehead, chest, and gluteal regions. On arrival, the patient's vital signs were normal. Hypotonia, dysarthria, and bilaterally ruptured tympanic membranes were observed. Cardiac and pulmonary examinations were within normal limits.

The initial electrocardiography (ECG) showed signs of inferolateral ischaemia. Echocardiography showed decreased motions in the apical and lateral wall of left ventricle. Computed tomography (CT) of the head displayed a mild cerebral oedema. The laboratory data obtained on admission were within normal limits except serine creatine kinase (861 U/l) and creatine-kinase muscle band (CK-MB) (75 U/l) values. Medical and family history was unremarkable. Fluid replacement and anti-oedema treatment (mannitol at a dose 


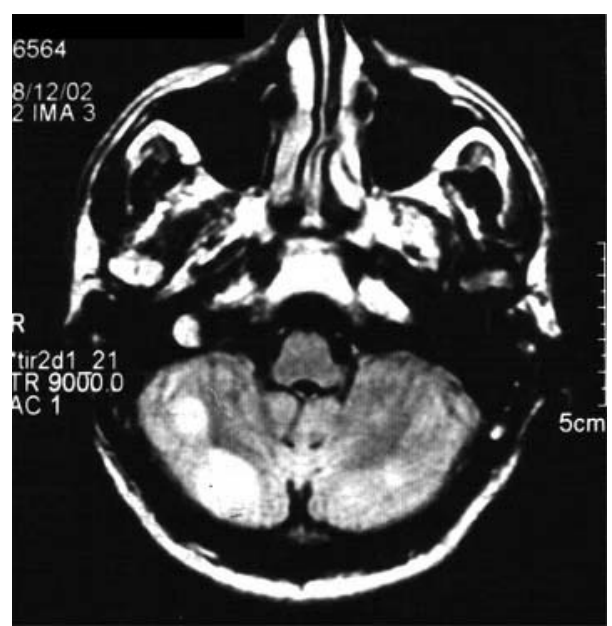

Figure 1 FLAIR weighted MRI scan shows hyperintens areas in the bilateral cerebellar regions.

of $0.5 \mathrm{mg} / \mathrm{kg}$ and hyperventilation $100 \% \mathrm{O}_{2}$ via face mask) were started.

On the third day of admission, GCS score was 14/15 (E4, M6, V4) although no difference from the previous CT examination was identified. On the fourth day, the patient was able to walk with support despite a significant ataxia, which led the clinicians to suspect a cerebellar disorder. MRI examination obtained on the fourth day showed an ischaemia predominantly in the right parietal, temporal, and frontal lobes and bilateral cerebellar hemispheres (fig l). The patient was discharged after seven days. After one month, dysarthria and hypotonia were found to have resolved, but ataxia did not improve completely.

\section{DISCUSSION}

Effects of lightning strikes range from minor to life threatening. Only about $20 \%$ of people who are struck are killed, the remaining $80 \%$ having various degrees of disability. ${ }^{3}$ Immediate manifestations in survivors of lightning include changed consciousness, disorientation, impaired vision; ruptured ear drums, hearing loss; seizures, paralysis, burns on the skin, internal burns to organs and tissues and finally, cardiac arrest. ${ }^{4}$ Although rare, serious lightning injuries are likely to primarily cause cardiac and neurological injuries. Changes in the cardiac rhythm may occur, although the heart will usually resume its normal rhythm quickly. ECG abnormalities are common, but generally resolve spontaneously. ${ }^{5}$ In this case, signs of inferolateral ischaemia were detected on ECG and decreased motions of apex and lateral wall of left ventricle were identified by two dimensional echocardiography. In combination with neurological symptoms, the isoenzyme of creatine kinase with brain subunits (CK-BB band) may be raised, but this has not been proved to be of major prognostic significance. In this case, both CK and CK-MB were found increased, while the remaining laboratory data were unremarkable. This condition was not a new entity with regard to the literature. ${ }^{6}$
Neurological complications of lightning range from loss of vision to hypoxic encephalopathy. ${ }^{7}$ CT scan of the head is indicated in patients with a loss of consciousness, both to detect any injury directly caused by the lightning strike and to exclude secondary blunt trauma to the head and cerebral tissues. In this case, cerebral oedema was detected on CT examination. Confusion and loss of consciousness found in this case might be as a result of direct passage of the current through the brain. ${ }^{8}$ Nevertheless, these data could not explain the development of ataxia in the victim. Therefore, MRI was performed and ischaemia was identified predominantly on cerebellar hemispheres. CT scan of the head is usually the preferred diagnostic modality in the acute management of neurological complications. ${ }^{9}$ However, Janus et al reported that 10 victims with lightning injury had some neurological complications, but only two of the patients had positive radiological findings on CT examination. Milton et a ${ }^{10}$ was the first author who reported that early white matter changes were associated with lightning injury on MRI examination. Several mechanisms were alleged to explain this phenomenon: direct electrolytic effect of the electrical charge passing through the brain, heating effect of the electrical current, and mechanical trauma of the lightning stroke.

In conclusion, clinicians should not overlook lightning injury in the management of acute cerebellar ischaemic insult and relevant clinical findings in adults. While CT scan of the head may be insufficient in the establishment of a diagnosis of cerebellar infarction, MRI may prove superior in the diagnosis of such complications.

\section{Authors' affiliations}

S Aslan, S Yilmaz, Department of Emergency Medicine, Atatürk University, School of Medicine, Erzurum, Turkey

O Karcioglu, Department of Emergency Medicine, Dokuz Eylül University, School of Medicine, İzmir, Turkey

Correspondence to: Dr S Aslan, Atatürk University, School of Medicine, Department of Emergency Medicine, 25090 Erzurum, Turkey; sahinaslan29@hotmail.com

Accepted for publication 28 February 2003

\section{REFERENCES}

1 Lopez RE, Holle RL. Demographics of lightning causalties. Semin Neurol 1995; 15:286-95.

2 Janus TJ, Barrash J. Neurologic and neurobehavioral effects of electric and lightning injuries. J Burn Care Rehabil 1996;17:409-15.

3 Cooper MA, Andrews CJ, Holle RL, et al. Lightning injuries. In: Auerbach P, ed. Wilderness medicine. 4th ed. St Louis: Mosby, 2001.

4 Cooper MA, Andrews CJ. Lightning injuries. In: Auerbach PS, Geehr ED, eds. The management of wilderness and environmental injuries. 3rd ed. St Louis: Mosby Year Book, 1995

5 Lichtenberg R, Dries D, Ward K. Cardiovascular effects of lightning strikes. J Am Coll Cardiol 1993;21:531-6.

6 Epperly TD, Stewart JR. The physical effects of lightning injury. J Fam Pract 1989;29:267-72.

7 Browne BJ, Gaasch WR. Electrical injuries and lightning. Emerg Med Clin North Am 1992;10:211-26.

8 Graber J, Ummenhofer W, Herion $\mathrm{H}$. Lightning accident with eight victims: case report and brief review of literature. J Trauma 1996;40:288-90.

9 Cherington M, Yarnell P, Lammeraste D. Lightning strikes: nature of neurological damage in patients evaluated in hospital emergency departments. Ann Emerg Med 1992;21:575-8.

10 Milton WJ, Hal O'Dell R, Warner EG. MRI of lightning injury: early white matter changes associated with cerebral dysfunction. J Okla State Med Assoc 1996;89:93-4. 


\section{Acute urinary retention attributable to sacral herpes zoster} J Acheson, D Mudd

Emerg Med J 2004;21:752-753. doi: 10.1136/emj.2003.009928

Acute urinary retention in women is uncommon. A 63 year old woman presented with suprapubic pain, a palpable bladder, and multiple grouped vesicles on the right buttock. Catheterisation showed a residual of $2000 \mathrm{ml}$. A case is reported of acute urinary retention secondary to herpes zoster infection of the sacral nerves (S2-4).
A 63 year old woman presented to the accident and emergency department complaining of suprapubic pain and an inability to void urine. Over the previous few days she had noticed that her urinary stream was declining. There was no previous history of urological problems. However, the patient was prone to constipation, her last bowel movement being two days previously. History was significant for a laminectomy performed 25 years earlier.

Physical examination showed a bladder distended to the umbilicus and on rectal examination there was soft faeces present. There was no neurological deficit in the perineum or lower limbs, but multiple grouped vesicles were noticed on the right buttock. These had been developing over the previous four to five days (fig 1). The patient recalled having chicken pox as a child but had no previous skin complaints.

A bladder catheter was inserted draining a residual volume of $2000 \mathrm{ml}$. Direct urine microscopy was normal, and a mid-stream urine specimen did not detect any significant bacterial growth. The initial blood tests were consistent with a post-obstructive uropathy (urea $10.5 \mathrm{mmol} / \mathrm{l}$, creatinine $157 \mu \mathrm{mol} / \mathrm{l}$.) This however resolved after catheterisation (urea $6.0 \mathrm{mmol} / \mathrm{l}$, creatinine $115 \mu \mathrm{mol} / \mathrm{l}$.) A swab was taken from the right buttock and polymerase chain reaction analysis confirmed the presence of varicella zoster virus.

Further investigation included a normal ultrasound scan of renal tracts and pelvis. Cystoscopy showed a healthy bladder with a large capacity and a rigid sigmoidoscopy to $15 \mathrm{~cm}$ was normal.

The patient was given oral acyclovir. A trial removal of catheter three weeks later was unsuccessful but when the catheter was removed a further eight weeks later, the patient was able to pass urine as normal.

\section{DISCUSSION}

Acute urinary retention is more common in men than women. Recorded causes in women have included bladder stones and tumours, psychogenic and rarely a rectal mucocele. ${ }^{1}$

We report a case of acute urinary retention secondary to herpes zoster infection of the sacral nerve roots (S2-4). This cause was first reported in the literature in $1890 .^{2}$ Since then less than 150 cases have been reported worldwide. ${ }^{3}$ Herpes zoster is an infection attributable to the varicella virus. A painful vesicular rash is noted that affects one or more dermatomes and is associated with an inflammatory reaction (nerve cell necrosis, lymphocytic infiltration, and

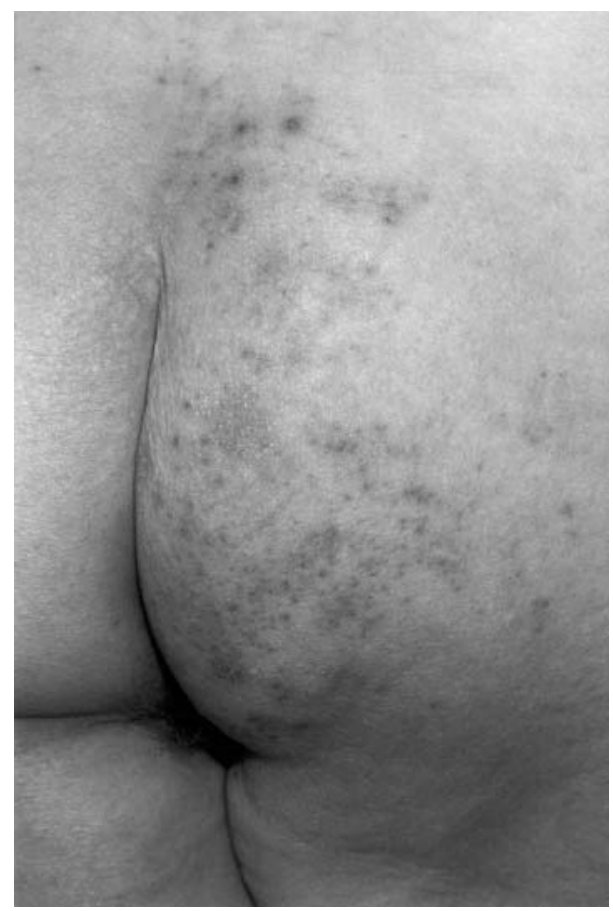

Figure 1 Multiple grouped vesicles on the right buttock.

haemorrhage). ${ }^{5}$ A neuropathic bladder develops because of involvement of the detrusor reflex.

It is reported that herpes zoster affects men and women equally, and that the characteristic rash is most often unilateral. ${ }^{6}$ Varicella zoster is more commonly found in the thoracolumbar segments with involvement in the sacral area being uncommon. ${ }^{7}$ It usually presents in the sixth to eighth decades, as in this case. However it has been reported in patients in their 20s. ${ }^{8}$

Herpes zoster infection in the sacral region has also been implicated in bowel dysfunction. Constipation can occur simultaneously because of anal sphincter dysfunction. ${ }^{8}$

The cystoscopy in this patient showed a healthy bladder with a large capacity. However, in previous cases there have been intravesical lesions associated with an inflamed bladder wall. ${ }^{9}$ In this case cystoscopy was carried out early on, therefore the lesions may not have become apparent.

In conclusion, the prognosis for acute urinary retention secondary to herpes zoster of S2-4 is usually benign. The detrusor muscle should recover to normal function. Initial treatment is by catheterisation, either urethral or suprapubic if indicated. A course of oral acyclovir is required, and treatment of secondary bacterial infection if present. Follow up urodynamic studies will confirm the return of detrusor function. We would like to make any practising physician aware that this is an uncommon cause of a commonly diagnosed condition. 
Authors' affiliations

J Acheson, D Mudd, Department of Surgery, Antrim Area Hospital, Northern Ireland

Correspondence to: Dr J Acheson, c/o Department of Surgery, Antrim Area Hospital, 45 Bush Road, Antrim BT28 3QE, Northern Ireland; achesonjonny@hotmail.com

Accepted for publication 12 September 2003

\section{REFERENCES}

1 Dauleh MI, Byrne DJ. Unusual cause of acute retention of urine. J R Coll Surg Edinb 1995;40:197.
2 Davidsah H. Communication. Berl Munch Tierarztl Wochenschr 1890;27:695.

3 Broseta E, Osca JM, Morera J, et al. Urological manifestations of herpes zoster. Eur Urol 1993;24:244-7.

4 Yamanishi T, Yasuda K, Sakakibara R, et al. Urinary retention due to herpes virus infection. Neurourol Urodyn 1998;17:613-19.

5 Clason AE, McGeorge A, Garland C, et al. Urinary retention and granulomatous prostatitis following sacral herpes zoster infection. $\mathrm{Br} J$ Uro 1982;54:166-9.

6 Ginsberg PC, Harkaway RD, Elisco AJ. Rare presentation of acute urinary retention secondary to herpes zoster. J Am Osteopath Assoc 1998;98:508-9.

7 Oates JK. Greenhouse PRDH: Retention of urine in anogenital herpetic infection. Lancet 1978;i:691-2.

8 Cohen LM, Fowler JF, Owen LG, et al. Urinary retention associated with herpes zoster infection. Int J Dermatol 1993;32:24-6.

9 Tsai Hn, Wu WJ, Huang SP, et al. Herpes zoster induced neuropathic bladder-a case report. Kaohsiung J Med Sci 2002;18:39-44. 